\title{
An Outline of a Theory of Affordances
}

\author{
Anthony Chemero \\ Scientific and Philosophical Studies of Mind Program \\ Department of Psychology \\ Franklin and Marshall College
}

\begin{abstract}
A theory of affordances is outlined according to which affordances are relations between the abilities of animals and features of the environment. As relations, affordances are both real and perceivable but are not properties of either the environment or the animal. I argue that this theory has advantages over extant theories of affordances and briefly discuss the relations among affordances and niches, perceivers, and events.
\end{abstract}

The primary difference between direct and inferential theories of perception concerns the location of perceptual content, the meaning of our perceptions. In inferential theories of perception, these meanings arise inside animals, based on their interactions with the physical environment. Light, for example, bumps into receptors, causing a sensation. The animal (or its brain) performs inferences on the sensation, yielding a meaningful perception. In direct theories of perception, on the other hand, meaning is in the environment, and perception does not depend on meaning-conferring inferences; instead, the animal simply gathers information from a meaning-laden environment. However, if the environment contains meanings, then it cannot be merely physical. This places a heavy theoretical burden on direct theories of perception, a burden so severe that it may outweigh all the advantages to conceiving perception as direct. ${ }^{1}$ This is because direct theories of perception require a new ontology, one that is at odds with today's physicalist, reductionist consensus that says the world just is the physical world, full stop.

Requests for reprints should be sent to Anthony Chemero, Scientific and Philosophical Studies of Mind Program, Department of Psychology, Franklin and Marshall College, Lancaster, PA 17604-3003. E-mail: tony.chemero@fandm.edu

${ }^{1}$ Among these advantages are that direct perception is more true to phenomenology, is more realistic from an evolutionary point of view, and short-circuits traditional skeptical worries. 
Without a coherent understanding of what the world is like, such that it can contain meanings and is not merely physical, direct perception is simply indefensible. Thus, like earlier theories that take perception to be direct (e.g., Heidegger, 1962; James, 1912/1976), James Gibson's ecological psychology $(1966,1979)$ includes an ontology, his theory of affordances (1979).

Gibson's (1979) first description of affordances is deceptively simple: "The affordances of the environment are what it offers the animal, what it provides or furnishes, either for good or ill" (p. 127). An affordance, this seems to imply, is a resource that the environment offers any animal that has the capabilities to perceive and use it. As such, affordances are meaningful to animals: They provide opportunity for particular kinds of behavior. Thus, affordances are properties of the environment but taken relative to an animal. So far, so good. It is unfortunate that, two pages later, Gibson's valiant, plainspoken attempt to make clear how much his theory of affordances differs from standard physicalist, reductionist ontology ends up just being confusing:

An affordance is neither an objective property nor a subjective property; or it is both if you like. An affordance cuts across the dichotomy of subjective-objective and helps us to understand its inadequacy. It is equally a fact of the environment and a fact of behavior. It is both physical and psychical, yet neither. An affordance points both ways, to the environment and to the observer. (p. 129)

This description makes affordances seem like impossible, ghostly entities, entities that no respectable scientist (or science-worshipping analytic philosopher) could have as part of their ontology. The purpose of this article is to provide a description of affordances that makes them more ontologically respectable yet still does justice to Gibson's conception.

\section{DEFINING AFFORDANCE: 1. PREVIOUS VIEWS}

This is, of course, not the first attempt to develop a coherent theory of affordances. It is worthwhile to say a few things about previous attempts, in order to see what is different about the theory outlined here. Previous (post-Gibson) attempts to set out an ontology of affordances have typically assumed that affordances are properties of the environment (Heft, 1989, 2001; Michaels, 2000; Reed, 1996; Stoffregen, 2000; Turvey, 1992). These authors have agreed that affordances are animal-relative properties of the environment. In particular, affordances are properties of the environment that have some significance to some animal's behavior. To the extent that there is disagreement among these authors, it focuses on two things: (a) what kind of animal-relative properties of the environment affordances are, and (b) what it is about animals that affordances are relative to.

There are two different views concerning the type of animal-relative properties of the environment that are affordances. Reed (1996) argued that affordances are 
resources in the environment, properties of objects that might be exploitable by some animal, and he linked this understanding of affordances to evolution by natural selection. Indeed, Reed took this linkage between affordances and natural selection to be the most important thing about ecological psychology: "The fundamental hypothesis of ecological psychology ... is that affordances and only the relative availability (or nonavailability) of affordances create selection pressure on animals; hence behavior is regulated with respect to the affordances of the environment for a given animal" (p. 18).

The resources in the environment are the source of selection pressure on animals, causing them to develop perceptual systems that can perceive those resources. Those resources that some species of animal evolve the ability to perceive are affordances for members of that species. This selectionist view of affordances, in which they are environmental resources that exist prior to the animals that come to perceive and use them, is also endorsed by Stoffregen (2000). (Stoffregen, this issue, does not endorse this view, however.)

In contrast to this selectionist view of affordances, which ties them closely to evolution by natural selection, is the view espoused by Turvey (1992), according to which ecological psychology is tied more closely to physics than to evolutionary biology. According to Turvey, affordances are dispositional properties of the environment. Dispositional properties are tendencies to manifest some other property in certain circumstances. "Being fragile" is a common dispositional property. Something is fragile just in case it would break in certain circumstances, particularly circumstances in which it is struck sharply. Thus dispositional properties are conceivable only when paired with actualizing circumstances, circumstances in which the disposition becomes manifest - the glass is fragile only if there are possible circumstances in which it might shatter. To say that affordances are dispositional properties of the environment, then, is to say that the environment is such that, in some circumstances, certain other properties will become manifest. So, for example, the affordance "being edible" is a property of objects in the environment only if there are animals that are capable of eating and digesting the object.

Notice that, unlike Reed's (1996) view of affordances as resources, Turvey's (1992) account of affordances as dispositions is nonselectionist. Dispositions depend on possible actualizing circumstances; for example, nothing is soluble if there are no solvents. If affordances are dispositions, they depend on the possible presence of animals that can actualize them. Affordances, in Turvey's preferred language, must be complemented by properties of animals. So, an object can be edible only if there are animals that can eat and digest it. Given this, contrary to Reed's fundamental hypothesis, affordances per se cannot exert selection pressure on animals. Properties of the environment are not affordances in the absence of complementary properties of animals.

Turvey's (1992) insistence that affordances must be complemented by properties of animals brings me to the second difference among accounts of affordances: If affordances are animal relative, then we should wonder what it is about animals that affordances are relative to. Turvey proposed that affordances are comple- 
mented by abilities or, more technically, effectivities (Shaw, Turvey, \& Mace, 1982). Effectivities, like affordances, are dispositions, and as such they must have be complemented by properties that lead to their actualization. Effectivities are properties of animals that allow them to make use of affordances. Effectivities and affordances are, thus, inseparable according to Turvey. They complement one another. I interpret Michaels (2000) as endorsing this view. Another candidate for the aspect of animals to which affordances are relative is body scale. This view of affordances, endorsed by Heft $(1989,2001)$, is suggested by empirical studies of affordances, which follow Warren's (1984) classic study of stair-climbing affordances in quantifying affordances with $\pi$ numbers, ratios between measures of body scale, and measures of an environmental property. ${ }^{2}$ I take it that this is the reason that Stoffregen's (2000) discussion of affordances focuses on their relation to body scale. Heft (1989) provided a second reason for taking body scale to be the properties of animals to which the affordances of the environment are related. Understanding affordances as body-related, Heft (1989) suggested, can do justice to the phenomenological insights of Merleau-Ponty (1962) and the profound influence those insights had on Gibson.

To summarize this brief discussion of some of the previous theoretical work on affordances, we can say the following: First, everyone agrees that affordances are animal-relative properties of the environment. Second, there is some disagreement over whether these properties exist without animals. This disagreement comes to an argument over whether affordances are resources that guide natural selection or dispositional properties of the environment that must be complemented by some property of animals. Third, there is disagreement over what the relevant properties of animals are: abilities (or effectivities) or body scale.

The understanding of affordances outlined in this article avoids these two controversies. It can do so by disagreeing with the premise on which they are based: the claim that affordances are animal-relative properties of the environment. I argue that affordances are not properties of the environment; indeed, they are not even properties. Affordances, I argue, are relations between particular aspects of animals and particular aspects of situations. Saying exactly what this means and what the aspects of animals and situations in question are is my primary task in the rest of this article.

\section{A FEW CRITICAL COMMENTS}

In this section I argue very briefly against the idea that affordances are properties of the environment. This argument has two parts. First, I argue that affordances are not properties, or at least not always properties. Second, I argue that affordances

\footnotetext{
${ }^{2}$ Heft (1989) also drew on Merleau-Ponty (1962) to derive a theory of the role of culture in affordances. I do not address this aspect of Heft's theory here.
} 
are not in the environment. Both these arguments have appeared previously (Chemero, 2001, 2003), so I review them rather cursorily.

\section{Affordances and Properties}

In my 2001 article (Chemero, 2001), I argued that it was vital to distinguish between features and properties when discussing affordances. The purpose of that discussion was to counter Michaels's (as in Michaels, Zeinstra, \& Oudejans, 2001) claim that perceiving ball-punching affordances is perceiving something about oneself, not something about the environment. This, I argued, is true only if one fails to realize that there is a more primitive way of perceiving the environment, involving what Strawson (1959) called feature placing (see also Smith, 1996). Feature placing is easiest to understand in contrast to the perception of objects with properties. Compare, for example, realizing that your car is dented with realizing that it is raining. In the former case, the perception of a property of the car, you must (a) perceive a particular entity; (b) know its identity, that it is your car; (c) know what it is to be dented; and (d) perceive that this particular entity (your car) has this particular property (being dented). In the last case, the placing of a feature, there is no need to know anything about any particular entity. All that is necessary is the ability to recognize a feature of situations (raininess). To see this, consider that the $i t$ in "it is raining" is never the same thing; it refers to a situation (what is going on right here, right now) that will never appear again.

Drawing attention to this distinction between placing features and perceiving properties of objects is relevant to the perception of affordances, because Michaels (2000) argued that when we perceive ball-punching affordances, we perceive that "it is time to flex the elbow." This, she argued, is perceiving something about oneself, not about the environment. The recognition of feature placing calls this into question. Perceiving that it is time to flex the elbow is like perceiving that it is raining: It is a matter of perceiving that the situation as a whole has a certain feature, that the situation as a whole supports (perhaps demands) a certain kind of action. All of this is to say that perceiving affordances is placing features, and because features are not properties, any view of affordances that takes them to be properties is mistaken.

\section{Affordances and the Environment}

Following on the argument just outlined, it is a small step to see that affordances cannot be properties, or even features, of the environment alone. I have just argued that affordances are features of whole situations. Animals are, of course, usually crucial parts of these whole situations, so perceiving something about the whole situation cannot always be just perceiving something about the environment, divorced from the animal. Thus, as Stoffregen (this issue) suggests, affordances must belong to animal-environment systems, not just the environment. Although I 
agree with Stoffregen on this point, I argue for something more specific: that affordances are relations. To do this, I review an argument from my 2002 article (Chemero, 2003) concerning Heft's (2001) discussion of the relation between James Gibson and William James.

In Ecological Psychology in Context, Heft (2001) argued quite convincingly that Gibson's ecological psychology is a descendent of the radical empiricism of James. To the radical empiricist, perception is direct because it is an act that includes the thing perceived. This leads to what James called the problem of two minds. Suppose you and I both perceive the same pint of Guinness. The pint, according to radical empiricism, is part of both my perception and yours. However, this leads to a problem of mereology: If the pint is part of both our perceptions, then our minds overlap. This, James thought, is in direct conflict with the to-him-obvious fact that our minds are private. The problem of two minds, then, is as follows: If perception is direct, and two individuals can perceive the same object, then how can their minds be truly separate? James struggled with the problem of two minds throughout his later years and never reached a satisfying resolution. This same problem affects any theory of direct perception, including Gibson's ecological psychology. Affordances are part of the act of perception, so if you and I both perceive the affordance "potability" of the pint of Guinness, our perceptions overlap. Our experiences, and hence minds, are not private.

The solution to this problem is apparent in another of the main tenets of Jamesian radical empiricism. According to radical empiricism, everything that is experienced is equally real. Among the things we experience are relations between things, so relations are real, with the same status as the things that stand in relations. To solve the problem of two minds, suppose that perceivables are relations between perceivers and aspects of situations. If that is true, you and I can both perceive the potability of the Guinness, without our perceptions overlapping. You will perceive the relation between you and the pint, whereas I will perceive the relation between me and the pint, and our perceptions can remain private. The key to this solution, though, is that what we perceive, the affordance potability, is not in the environment alone. It is, instead, the relation between the perceiver and the environment. This point, that affordances are relations, is the key to the theory of affordances I describe in the following sections.

\section{DEFINING AFFORDANCE: 2. A NEW DEFINITION}

I have said several times that affordances are relations between animals and features of situations. I now spell out in detail what that means. To begin, here is the basic logical structure of affordances, on which I expand later.

Affords- $\phi$ (environment, organism), where $\phi$ is a behavior. 
Translated literally into English, this means "The relation 'affords- $\phi$ ' holds between 'environment' and 'organism"'; translated more loosely and colloquially, this means "The environment affords behavior $\phi$ to the organism." To get an idea what this means, and what it means to say that affordances are relations, compare it with a more familiar relation.

Taller-than (Shaquille, Tony).

This says that Shaquille is taller than Tony. Notice first that the only objects in this relation are Shaquille and Tony. The taller-than is not inherent in either of them but depends on both of them for its existence. Affords- $\phi$ is like taller-than in this respect: It is neither of the person, nor of the environment, but rather of their combination. Second, the affordance is not an extra thing in any of the usual senses of "thing." Yet it exists nonetheless, and, like the fact that Shaquille is taller than Tony, is quite perceivable. Taking affordances to be relations, despite the fact that they are not things in the usual sense, is quite plausible in light of Heft's (2001) account of Gibson as a Jamesian radical empiricist (Chemero, 2003). As noted earlier, the radical empiricist relations are perceivable, and anything perceivable is real.

The formal definition of affordances as relations between organisms and environments is incomplete. Which aspect of the environment is related to which aspect of the organism, and in what way? If affordances are relations, what is it to perceive affordances? In answering these questions, I flesh out this definition of affordances.

\section{The Environmental Relata}

As discussed earlier and in my 2001 article (Chemero, 2001), perceiving affordances is placing features, seeing that the situation allows a certain activity. Thus, the environmental relata in affordances must be features, not properties. The only further comment here is that this is in direct disagreement with Turvey (1992), who pronounced that "3.1 There are only propertied things" (p. 176). Situations are not things; features are not properties.

\section{The Organismal Relata}

Ever since Warren's (1984) groundbreaking experiments on stair climbing, it has been (tacitly) assumed that the aspect of animals that determines what the environment affords, the organismal relata in the affordance relation, is some aspect of body scale. Warren, in attempting to quantify affordances for stair climbing, quantified them as unitless $\pi$ numbers, the ratio between leg length and riser height. The affordance climbability is then identified as this ratio. Subsequent experiments identified affordances similarly, as ratios between body scale and some bit of the en- 
vironment measurable in the same units (e.g., see work on gap crossing by Burton, 1992, 1994; Cornus, Montagne, \& Laurent, 1999; Jiang \& Mark, 1994; Mark 1987; Mark, Jiang, King, \& Paasche, 1999). Many experimentalists, I suspect, have not given much thought to this fact, simply assuming that what they are measuring are affordances. Given the preceding discussion, it might seem natural to say that the affordance is expressed as the following relation:

affords-climbing (my leg length, riser height),

which is perceivable whenever the ratio of my leg length to the riser height is within a certain range. Doing so is a mistake: One must remember that body scale is just an easily quantifiable stand-in for ability. Most theoretical work on affordances does not make this mistake, pointing out that the animal-side counterparts of affordances are effectivities (e.g., Michaels, 2000; Reed, 1996; Stoffregen, 2000; Turvey, 1992; see also previous discussion). ${ }^{3}$

Although body scale is easily measured, it is only occasionally a good placeholder for ability. In most cases there is not a tight relation between body scale and ability. Indeed, recent research seems to be calling even the paradigm cases of body-scaled studies of affordances into question. Consider, for example, recent research by Cesari, Formenti, and Olivato (2003) on stair-climbing affordances. The studies reported by Cesari et al. indicate that people perceive stair climbing and descending affordances not as the ratio between leg length and riser height (as Warren, 1984, held) but rather as a relation between stepping ability and riser height. In Cesari et al.'s study, participants were asked to determine the highest step they could climb; the authors called this variable perceived riser height. Participants were then asked to (a) approach the steps from a distance of $4 \mathrm{~m}$, as if they were going to climb them; (b) stop; and then (c) climb the stair. The important variable here was distance from the participant's foot to the stair bottom when the participant stopped. It was found that different types of participants (children, young adults, older adults) had the same optimal ratio of distance from step to riser height, which is to say that they had the same ratio for the highest step they could climb. This ratio is a function of stair-climbing ability, not leg length. To see this, consider further results from the same set of studies. First, there was an important difference between older adults, on the one hand, and younger adults and children, on the other: Older adults maintained the optimal ratio of distance from step to step height for steps as much as $10 \%$ shorter than the maximum steps they could climb, whereas in younger participants, the ratio changed significantly for steps $10 \%$ shorter than the maximum

\footnotetext{
${ }^{3}$ W. H. Warren (personal communication, July 2002), who is responsible for the introduction of $\pi$ numbers into ecological psychology, agrees that body scale is just an easily measurable substitute for ability. Saying so, of course, in no way downplays the importance of Warren's studies and, more generally, $\pi$ numbers.
} 
climbable. Finally, Cesari et al. found that older adults were significantly less flexible than younger adults and children.

Put together, Cesari et al.'s (2003) results indicate quite strongly that the relevant animal-side variable for stair-climbing affordances is climbing ability. First, there is an optimal ratio of height to distance for stair climbing, and all participants used this information to determine the tallest step they could climb. Less flexible older adults maintained this ratio even for steps lower than their highest climbable steps; young adults and children did not. Given the flexibility results, older adults have different stair-climbing abilities than young adults and children. They also use the ratio differently, choosing to maintain the optimal ratio even for situations in which they can climb stairs relatively easily. So, the ratio, which is the aspect of the environment perceived in determining climbability, is perceived in terms of ability. ${ }^{4}$

Affordances, then, are relations between the abilities of organisms and features of the environment. Affordances, that is, have this structure:

Affords $-\phi$ (feature, ability).

\section{Affordances, Abilities, and Dispositions}

Thus far, I have been using the words ability and effectivity more or less interchangeably. There are two things about effectivities as they are typically discussed that makes them different from abilities, however. First, effectivities are defined as the organismal complement to affordances qua properties of the environment (Shaw et al., 1982; Turvey, 1992; Warren, 1984). I have been arguing that affordances are not properties of the environment and that thus there is no need for complementing property in the organism. Second, at least in Turvey's article, effectivities are defined as dispositions. Abilities are not dispositions.

The problem with seeing abilities as dispositions is that, when coupled with the right enabling conditions, dispositions are guaranteed to become manifest. The soluble solid sugar will always dissolve in water in suitable conditions. This is not true of abilities. Having the ability to walk does not mean that one will not fall down even in the ideal conditions for walking. (Millikan, 2000, made this point forcefully; the remainder of this paragraph is based on her analysis of abilities. See also Millikan, 1984.) To point this out is to point out that there is something inherently normative about abilities. Individuals with abilities are supposed to behave in particular ways, and they may fail to do so. Dispositions, on the other hand, never fail; they are simply not in the appropriate circumstances to become manifest. A better way to understand abilities is as functional properties of animals. Functional

\footnotetext{
${ }^{4}$ Chemero, Klein, and Cordeiro (2003) provided preliminary evidence that gap-crossing affordances are also perceived in terms of ability, not leg length. The evidence is only suggestive, though.
} 
properties of animals depend on the individual animal's developmental history or the evolutionary history of the species. They are properties of the animal that came to play the role they do in the behavioral economy of the animal because, at some point in the past, they were helpful in helping the animal (or its ancestor) survive, reproduce, or flourish. Yet, even in circumstances identical to those in which they were helpful in the past, functional properties can fail to become manifest; there can, that is, be a malfunction. By taking abilities-the animal side relata in the affordance relation - to be functional properties, we can account for the fact that even on a firm surface, with no wind, while perfectly healthy and sober, I may fail in my attempt to climb a step that affords climbing for me. This is inconceivable in the case of dispositions, which necessarily become manifest whenever their actualizing circumstances are present.

This analysis of abilities, as functional properties and not dispositions, has a further noteworthy consequence: Because functional properties depend on evolutionary history, and affordances are partly constituted by functional properties, affordances are tied to evolution. This makes ecological psychology a branch of biology and a truly ecological science. Notice, however, that it does so without being selectionist in the way Reed's (1996) understanding of affordances (and hence ecological psychology) is; that is, it does not assume that affordances are resources that exert selection pressure. I take it that being evolutionary and ecological but not selectionist is a positive feature of the theory of affordances outlined here. First, there are (highly controversial) reasons from theoretical evolutionary biology to be skeptical of selectionist views of evolution. (This is well beyond the scope of this article. See Lewontin, 1994, and Godfrey-Smith, 1996, for some of the reasons.) Second, a selectionist view of the relation between affordances and animals fails to do justice to the mutuality of animal and environment (Gibson, 1979). If it is affordances that exert selection pressure, it cannot be, as Gibson suggested, that animals imply niches (sets of affordances; presented next) and vice versa. Rather, on the selectionist view, it is affordances that are in the driver's seat, and animals must conform to them over evolutionary history. According to the view being offered here, there is true animal-environment mutuality. Affordances, which are the glue that holds the animal and environment together, exist only in virtue of selection pressure exerted on animals by the normal physical environment. They arise along with the abilities of animals to perceive and take advantage of them.

\section{Perceiving Affordances}

Any account of the ontology of affordances requires a story about perceiving affordances. Perception for the ecological psychologist (as well as for the radical empiricist) is conceptualized as a relation between the perceiver and what is perceived. On the account of affordances outlined here, this relation looks like this:

Perceives [animal, affords- $\phi$ (feature, ability)]. 
This is the act of perception that is studied by ecological psychologists. An animal typically perceives only the affordance relation, though, and not the constituent relata; that is, most of the time the structure of the perception of affordances will be this:

Perceives [animal, affordance-of- $\phi]$.

This is surely the usual phenomenology of humans. I am normally not aware of anything about my climbing abilities or riser heights when I am perceive that I can climb a step. Humans, however, can - with training, and when so inclined-perceive things about their abilities and the features of the environment. Most nonhuman animals, perhaps all of them, are simply incapable of this.

\section{OK, BUT WHAT ABOUT ...}

Pretend for the moment that all of this is settled. Affordances are neither properties of the animal alone nor properties of the environment alone. Instead, they are relations between the abilities of an animal and some feature of a situation. They are not easily localizable physically but are nonetheless perfectly real and perfectly perceivable. ${ }^{5}$ There are still unanswered questions about affordances. In this last section I answer three of them: How are affordances related to niches? How are affordances related to events? Do affordances exist without animals?

\section{Affordances and Niches}

Gibson (1979) pointed out that a niche is the set of affordances for a particular animal. Different animals, with different abilities, may have physically colocated but nonetheless nonoverlapping niches. For example, a human and a bacterium may share a physical location (as when a bacterium is inside a human), but their niches will not overlap. As noted earlier, Gibson also suggested that this is the way to make sense of the mutuality of animals and environments. An animal's abilities imply an ecological niche. Conversely, an ecological niche implies an animal. Given the definition of affordances recommended, one can make sense of these facts about niches.

Start by taking organisms to be sets of abilities. These abilities will be interconnected, of course. An animal cannot have the ability to run if it maintains its posture; neither will it be able to climb a tree if it cannot affix itself to things (with suction, by grabbing, etc.). As Reed (1996) pointed out in his revealing analysis of action systems, all other abilities will depend on basic orienting abilities, abilities to

\footnotetext{
${ }^{5}$ Stoffregen (this issue) writes that affordances are emergent properties of the animal-environment system.
} 
maintain posture, and the like. There will also be a nested structure of abilities, in which larger abilities will be composed of smaller scale abilities. Each of an animal's abilities will have a set of situations in which it can be exercised. However, no larger scale ability will be exercisable in situations in which its component smaller scale abilities can be exercised; similarly, no ability will be exercisable in situations in which one or more more basic abilities on which it depends cannot be exercised. Thus, if walking is leg swinging, falling, and catching yourself, then walking will be impossible in situations in which one cannot swing a leg, or fall, or catch oneself. Walking will also not be possible in situations with no gravity, or too much gravity, or in which the atmosphere is in flames, because the basic orienting system on which walking depends is inoperable in these situations.

All this said, we can define an animal's niche as the set of situations in which one or more of its abilities can be exercised. To put this formally, start with the set of all possible situations, $\mathrm{S}$. For each ability $\mathrm{a}_{\mathrm{i}}$ there is a subset of $\mathrm{S}$, $\mathrm{s}_{\mathrm{i}}$, in which that ability can be exercised. Suppose an organism has abilities $a_{1} \ldots a_{n}$. That organism's niche will be the union of $s_{1} \ldots s_{n}$, for each ability $a_{1} \ldots a_{n}$ that the organism has.

\section{Affordances and Events}

In his article "Affordances and Events," Stoffregen (2000) argued that events, conceived as changes in the physical layout, are not perceivable according to ecological psychology. This is the case, he argued, because what we perceive are affordances, and events and affordances are of different ontological kinds. In response, I (Chemero, 2000) offered a new understanding of events, an understanding according to which event perception is not problematic for ecological psychology. Events, according to my article, are changes in the layout of affordances. In a later article (Chemero, Klein, \& Cordeiro, 2003), my colleagues and I provided experimental evidence that events so described can be perceived. (For details about, and defense of, this understanding of events, see Chemero, 2000; Chemero et al., 2003.) Here, I limit my discussion to the way that the definition of affordances as outlined affects the theory of events just described.

Assume that affordances are relations between the abilities of animals and features of environmental situations and that events are changes in the layout of affordances in the animal-environment system. How, then, do events happen? Equivalently, how do affordances change? Most changes in relations between the abilities of animals and environmental situations will be changes in environmental situations. Most events, that is, will result from changes in the environment. If the glass of water spills, the affordance drinkability disappears, because my drinking abilities are not appropriate for spilled water; once the apple falls from the tree it is edible, because my being able to grasp the apple is a necessary condition for my being able to eat it. In cases such as these, there are events, changes in affordances, without changes in abilities. There can also be changes in affordances without changes in the features of the environment. The very 
same stair no longer affords climbing to an individual whose stepping abilities have decayed because of old age. Because abilities typically change more slowly than the environment does, these events will happen less frequently than events that result from changes in the environment.

\section{Do Affordances Exist Without Animals?}

For all the noise ecological psychologists make about being realists, it is not obvious at the outset that ecological psychology is not a form of idealism, in which perceivables exist only when they are perceived. It is a small step from this to a rather silly global idealism, in which the world disappears whenever I close my eyes. Reed's (1996) conception of affordances as resources that exert selection pressure avoids this issue by making the case that affordances exist unproblematically, even without animals capable of perceiving them. Other understandings of affordances must face this problem. For Warren (1984), Turvey (1992), and Michaels (2000), who claim that affordances must be complemented by the effectivities of animals, the status of affordances is unclear in the absence of animals. Similarly, if affordances are relations between animals and situations, as I have argued, affordances depend in some sense on animals. The questions that must be answered are thus: In what sense do affordances depend upon animals? and Do affordances exist without animals?

As a first pass at answering these questions, I will co-opt some terminology from Dennett (1998), who distinguished between things that are lovely and things that are suspect. To see the distinction, consider that a female hippopotamus in a zoo might be lovely, even if no male hippopotamus has ever seen her. She is lovely just in case if a male hippopotamus were to see her, he would find her to be so. The key is that being lovely depends on a potential observer, not an actual act of observation. Compare this with being suspect. To be suspect, something actually has to be under suspicion. Being suspect requires an actual observer. Whether affordances exist without animals, whether ecological psychology is a form of idealism, is a matter of whether affordances are lovely or suspect. Affordances, we can see, are lovely. To put this in terms of the definition of affordances offered here, take some particular feature of some particular situation. That feature might exist just as it is even if there are no animals. There will be affordances in which that feature takes part as long as some animal exists with the appropriate ability. This is the case even if that animal is nowhere in the vicinity of the situation that affords something to it.

Affordances do not disappear when there is no local animal to perceive and take advantage of them. They are perfectly real entities that can be objectively studied and are in no way figments of the imagination of the animal that perceives them. So, ecological psychology is not a form of idealism. However, affordances do depend on the existence of some animal that could perceive them, if the right conditions were met. Because affordances, the primary perceivables according to ecological psychology, depend in this way on animals, the ontology of ecological 
psychology is not a simple form of realism. It is a form of realism about meaning, in which meaning (affordances) is a real aspect of the world and not just in our heads, as indirect theories of perception maintain.

Notice that my answer to these final questions can work for any theory of affordances that takes them to depend in some way on animals; that is, it works for Turvey (1992) and Michaels (2000), who think that affordances are dispositional properties of the environment that must be complemented by effectivities of the animal; it works for Heft $(1989,2001)$, who thinks that affordances are properties of the environment that are related to an animal's body scale; and it works for Stoffregen (this issue) and me, who think that affordances are relations. The contentions of this section, then, are the only ones in this article on which, I believe, most of ecological psychologists can agree. That makes this a good place to stop.

\section{ACKNOWLEDGMENTS}

I received helpful comments on these ideas from audiences at Franklin and Marshall College, the Center for the Ecological Study of Perception and Action at the University of Connecticut, the 2002 North American meeting of the International Society for Ecological Psychology (Oxford, OH), and the 2002 European Workshop on Ecological Psychology (Ile de Bandor, France). I am grateful to Colin Klein, Michael Penn, and Harry Heft for detailed comments on a draft of this article.

\section{REFERENCES}

Burton, G. (1992). Nonvisual judgement of the crossability of path gaps. Journal of Experimental Psychology: Human Perception and Performance, 18, 698-713.

Burton, G. (1994). Crossing without vision of path gaps. Journal of Motor Behavior, 26, 147-161.

Cesari, P., Formenti, F., \& Olivato, P. (2003). A common perceptual parameter for stair climbing for children, young and old adults. Human Movement Science, 22, 111-124.

Chemero, A. (2000). What events are. Ecological Psychology, 12, 37-42.

Chemero, A. (2001). What we perceive when we perceive affordances. Ecological Psychology, 13, 111-116.

Chemero, A. (2003). Radical empiricism through the ages. Contemporary Psychology, 48, 18-20.

Chemero, A., Klein, C., \& Cordeiro, W. (2003). Events as changes in the layout of affordances. Ecological Psychology, 15, 19-28.

Cornus, S., Montagne, G., \& Laurent, M. (1999). Perception of a stepping-across affordance. Ecological Psychology, 11, 249-267.

Dennett, D. (1998). Brainchildren. Cambridge, MA: MIT Press.

Gibson, J. J. (1966). The senses considered as perceptual systems. Boston: Houghton Mifflin.

Gibson, J. J. (1979). The ecological approach to visual perception. Boston: Houghton Mifflin.

Godfrey-Smith, P. (1996). Complexity and the function of mind in nature. New York: Cambridge University Press.

Heft, H. (1989). Affordances and the body: An intentional analysis of Gibson's ecological approach to visual perception. Journal for the Theory of Social Behavior, 19, 1-30. 
Heft, H. (2001). Ecological psychology in context: James Gibson, Roger Barker, and the legacy of William James's radical empiricism. Mahwah, NJ: Lawrence Erlbaum Associates, Inc.

Heidegger, M. (1962). Sein und Zeit [Being and time] (J. Macquarrie \& E. Robinson, Trans.). New York: Harper \& Row. (Original work published 1927)

James, W. (1976). Essays in radical empiricism. Cambridge, MA: Harvard University Press. (Original work published 1912)

Jiang, Y., \& Mark, L. (1994). The effect of gap depth on the perception of whether a gap is crossable. Perception $\mathcal{B}$ Psychophysics, 56, 691-700.

Lewontin, R. (1994). Inside and outside. Worcester, MA: Clark University Press.

Mark, L. (1987). Eye height-scale information about affordances: A study of sitting and stair climbing. Journal of Experimental Psychology: Human Perception and Performance, 13, 360-370.

Mark, L., Jiang, Y., King, S. S., \& Paasche, J. (1999). The impact of visual exploration on judgements of whether a gap is crossable. Journal of Experimental Psychology: Human Perception and Performance, 25, 287-295.

Merleau-Ponty, M. (1962). The phenomenology of perception (C. Smith, Trans.). New York: Routledge.

Michaels, C. F. (2000). Information, perception, and action: What should ecological psychologists learn from Milner and Goodale (1995)? Ecological Psychology, 12, 241-258.

Michaels, C. F., Zeinstra, E. B., \& Oudejans, R. R. D. (2001). Information and action in punching a falling ball. Quarterly Journal of Experimental Psychology, 54, 69-93.

Millikan, R. (1984). Language, thought and other biological categories. Cambridge, MA: MIT Press.

Millikan, R. (2000). On clear and confused ideas. New York: Cambridge University Press.

Reed, E. S. (1996). Encountering the world. New York: Oxford University Press.

Shaw, R., Turvey, M., \& Mace, W. (1982). Ecological psychology: The consequence of a commitment to realism. In W. Weimer \& D. Palermo (Eds.), Cognition and the symbolic processes (pp. 159-226). Hillsdale, NJ: Lawrence Erlbaum Associates, Inc.

Smith, B. C. (1996). On the origin of objects. Cambridge, MA: MIT Press.

Stoffregen, T. (2000). Affordances and events. Ecological Psychology, 12, 1-28.

Strawson, P. F. (1959). Individuals. London: Methuen.

Turvey, M. (1992). Affordances and prospective control: An outline of the ontology. Ecological Psychology, 4, 173-187.

Warren, W. H. (1984). Perceiving affordances: Visual guidance of stair climbing. Journal of Experimental Psychology: Human Perception and Performance, 10, 683-703. 